\title{
Involvement of Anti-Inflammatory, Antioxidant, and BDNF Up-Regulating Properties in the Antipsychotic-Like Effect of the Essential Oil of Alpinia Zerumbet in Mice: A Comparative Study With Olanzapine
}

Fernanda Yvelize Ramos de Araújo

Faculdade de Medicina da Universidade Federal do Ceara

Adriano José Maia Chaves Filho

Faculdade de Medicina da Universidade Federal do Ceara

Adriana Mary Nunes

Faculdade de Medicina da Universidade Federal do Ceara

Gersilene Valente de Oliveira

Faculdade de Medicina da Universidade Federal do Ceara

Patrícia Xavier Lima Gomes

Faculdade de Medicina da Universidade Federal do Ceara

Germana Silva Vasconcelos

Faculdade de Medicina da Universidade Federal do Ceara Jaqueline Carletti

Faculdade de Medicina da Universidade Federal do Ceara Manoel Odorico de Moraes

Faculdade de Medicina da Universidade Federal do Ceara

Maria Elisabete de Moraes

Faculdade de Medicina da Universidade Federal do Ceara

Silvânia Maria Mendes Vasconcelos

Faculdade de Medicina da Universidade Federal do Ceara

Francisca Cléa Florenço de Sousa

Faculdade de Medicina da Universidade Federal do Ceara

David Freitas de Lucena

Faculdade de Medicina da Universidade Federal do Ceara

Danielle Macedo ( $\boldsymbol{D}$ daniellesilmacedo@gmail.com )

Federal University of Ceara https://orcid.org/0000-0001-8980-9970 
Keywords: Schizophrenia, Ketamine model, Alpinia zerumbet, anti-inflammatory effects, Antipsychotic effects, antipsychotic side effects

Posted Date: March 1st, 2021

DOI: https://doi.org/10.21203/rs.3.rs-249536/v1

License: (1) This work is licensed under a Creative Commons Attribution 4.0 International License. Read Full License 


\section{Abstract}

The current drug therapy for schizophrenia effectively treats acute psychosis and its recurrence; however, this mental disorder's cognitive and negative symptoms are still poorly controlled. Antipsychotics present important side effects, such as weight gain and extrapyramidal effects. The essential oil of Alpinia zerumbet (EOAZ) leaves presents potential antipsychotic properties that need further preclinical investigation. Here, we aimed to determine the effects of EAOZ in the prevention and reversal of schizophrenia-like symptoms (positive, negative, and cognitive) induced by ketamine (KET) repeated administration in mice and putative neurobiological mechanisms related to this effect. To this end, we evaluated antioxidant (GSH, nitrite levels), anti-inflammatory [interleukin (IL)-6], and neurotrophic [brainderived neurotrophic factor (BDNF)] effects of this oil in hippocampal tissue. The atypical antipsychotic olanzapine (OLZ) was used as standard drug therapy. EOAZ, similarly to OLZ, prevented and reversed most KET-induced schizophrenia-like behavioral alterations, i.e., sensorimotor gating deficits and social impairment. EOAZ had a modest effect on the prevention of KET-associated working memory deficit. Compared to OLZ, EOAZ showed a more favorable side effects profile, inducing less cataleptic and weight gain changes. EOAZ efficiently protected the hippocampus against KET-induced oxidative imbalance, IL-6 increments, and BDNF impairment. In conclusion, our data add more mechanistic evidence for the anti-schizophrenia effects of EOAZ, based on its antioxidant, anti-inflammatory, and BDNF up-regulating actions. The absence of significant side effects observed in current antipsychotic drug therapy seems to be an essential benefit of the oil.

\section{Introduction}

Alpinia zerumbet (Alpinia zerumbet (Pers) Burtt. et Smith), popularly known in Brazil as "colônia", is a tropical ornamental plant used in some regions to control depression, psychomotor agitation, and anxiety (Satou et al. 2010).

Despite the prevalent use of Alpinia zerumbet in controlling neuropsychiatric symptoms, its oil's central effects started to be investigated only in the last decade. In this context, the oil presents an anxiolytic-like effect in mice (Satou et al. 2010, 2011). Additionally, our research group demonstrated a putative antipsychotic-like effect of the EOAZ with dopaminergic mechanisms' involvement (de Araújo et al., 2009). To this end, we firstly used screening models for the evaluation of novel antipsychotic drugs based on acute administration of dopaminergic drugs such as amphetamine and ketamine. In this initial protocol, we observed that the EOAZ counteracted the stereotypies and hyperlocomotion induced by these drugs (De Araújo et al. 2009, 2011). In vitro analysis revealed that this oil presents a marked brain antioxidant action, which, hence, can partially justify its neuroprotectant effects (De Araújo et al., 2011).

To date, schizophrenia drug treatment is not ideal (Gaebel et al. 2019). Antipsychotic drugs present a good control of positive symptoms but are of limited efficacy for treating cognitive and negative symptoms, also presenting important side effects (Campbell et al. 1999; Carpenter and Davis 2012). One common mechanism of these drugs is antagonizing dopaminergic receptors (Li et al. 2016). Despite this, 
the pathophysiology of schizophrenia, besides not fully understood, includes, but is not limited to alterations in glutamatergic neurotransmission (Javitt et al. 2012; Howes et al. 2015), and in neurotrophic mechanisms (Favalli et al. 2012), as well as oxidative damage and neuroinflammation (Muller and Schwarz 2006). Therefore, new anti-schizophrenia therapies targeting other pathophysiological alterations observed in schizophrenia and with proven efficacy against negative/cognitive symptoms with a safe and more tolerable profile of side effects is a challenging topic in the schizophrenia research field.

Ketamine (KET) repeated administration is a widely used animal model of schizophrenia. This model based on repeated administration can mimic positive, negative, and cognitive symptoms of this mental disorder (Monte et al. 2013b; Frohlich and Van Horn 2014). Dysfunctions of glutamatergic transmission and increased dopaminergic tone in the mesolimbic pathway accompany these behavioral alterations observed in this model (Irifune et al. 1991; Tan et al. 2012), as well as increased oxidative stress and neuroimmune changes (Monte et al. 2013c; Araújo et al. 2016). Ketamine-induced behavioral and neurochemical abnormalities are attenuated by atypical antipsychotics, confirming this model's predictive validity (Vasconcelos et al. 2015; Araújo et al. 2016).

In the present study, we hypothesized that the repeated administration of EOAZ could reverse the schizophrenia-like behavioral and neurochemical alterations induced by KET repeated administration. Hence, our primary outcome was evaluating the prevention or reversal of KET-induced behavioral alterations like positive, negative, and cognitive symptoms of schizophrenia by EOAZ, as well as the presence of side effects associated with antipsychotic drug therapy, namely catalepsy and weight gain. Our secondary outcome was determining the involvement of antioxidant, neurotrophic, and antiinflammatory mechanisms in the effects of this oil in the hippocampus, a brain area related to schizophrenia neurobiology (Harrison 2004).

\section{Material And Methods}

\subsection{Animals}

We used male Swiss mice (25-30 g; 6-11 animals/group) housed in standard environmental conditions ( $22 \pm 1^{\circ} \mathrm{C}$, humidity $60 \pm 5 \%, 12$-h light: 12 -h dark cycle) with free access to a standard commercial diet and with water freely available, following international recommendations (NIH 1996). The Animal Ethics Committee of the Universidade Federal do Ceará (UFC) approved the experimental protocol (number 106/2014).

\subsection{Plant material}

The essential oil was extracted from the leaves of A. zerumbet (EOAZ), collected from the Medicinal Plants Garden of the Laboratory of Natural Products of the Universidade Federal do Ceará, Ceará State, Brazil, during January 2015. A voucher specimen of A. zerumbet is at Herbarium Prisco Bezerra (\#10858). Researchers from the Department of Organic and Inorganic Chemistry of the UFC isolated the essential 
oil, according to the method described elsewhere (Craveiro et al. 1976). Briefly, freshly chopped plant leaves were placed in a glass flask, connected at one end to a glass vessel with water, and at the other end to a water-cooled condenser. The steam was percolated through the chopped plant leaves and collected in the condenser under boiling water. After condensation, the liquid phase with its solutes, here called 'aqueous extract', was separated from an oily phase, the essential oil. Gas chromatography and mass spectrometry (Shimadzu QP5050 GCMS gas chromatograph, Shimadzu Corporation, Kyoto, Japan) was used to determine the oil composition. The constituents were identified by a computer library search based on their retention indices and visual interpretation of the mass spectra (Adams 2009). The main constituents identified in the EOAZ were (\%): terpinene-4-ol, 25.7; 1,8-cineole, 24.61; $\gamma$-terpinene, 14.28. Supplementary Table 1 presents the complete list of EOAZ constituents with their respective chemical structure.

\subsection{Drugs}

The animals received oral doses of 100 or $200 \mathrm{mg} / \mathrm{kg}$ EOAZ dissolved in $2 \%$ tween 80 (Sigma-Aldrich, St. Louis, USA) or olanzapine (OLZ - $2 \mathrm{mg} / \mathrm{kg}$ - Zyprexa ${ }^{\circledR}$, Elli Lilly, Brazil), used, here as a standard antipsychotic. Ketamine hydrochloride (KET - Ketalar ${ }^{\circledR}$, Parke-Davis Lab, Brazil), at a dose of $20 \mathrm{mg} / \mathrm{kg}$, was administered intraperitoneally (IP) to induce schizophrenia-like alterations. The dose of OLZ was calculated based on body surface area (BSA) as described elsewhere (Reagan-Shaw et al. 2008). Based on this calculation, $2 \mathrm{mg} / \mathrm{kg}$ OLZ in mice is equivalent to the human therapeutic dose of $10 \mathrm{mg} /$ day OLZ. Previous studies on KET as a pharmacological animal model of schizophrenia guided KET dose choice (Monte et al. 2013c).

\subsection{Experimental Design}

We used two distinct protocols, namely prevention and reversal. In the prevention protocol, we aimed at mimicking the maintenance treatment phase of schizophrenia (Monte et al., 2013). In this protocol, the animals received a daily administration of vehicle, EOAZ (100 or $200 \mathrm{mg} / \mathrm{kg}$ ), or OLZ $2 \mathrm{mg} / \mathrm{kg}$ for 14 days. Between the 8th and 14th days of treatment, mice additionally received a daily injection of KET or vehicle (also called the control group) $30 \mathrm{~min}$ after EOAZ. Hence, the prevention protocol comprised the following groups: control, EOAZ100 + SAL, EOAZ200 + SAL, SAL + KET, EOAZ100 + KET, EOAZ200 + KET, OLZ + KET. The reversal protocol simulated an acute treatment of psychotic episodes (da Silva Araújo et al., 2017; Monte et al., 2013). Each animal received one daily injection of KET $20 \mathrm{mg} / \mathrm{kg}$ or vehicle for 14 days in this protocol. From the 8th day of treatment onwards, mice additionally received a daily oral administration of vehicle, EOAZ (100 or $200 \mathrm{mg} / \mathrm{kg}$ ), or OLZ $2 \mathrm{mg} / \mathrm{kg}$, with a 30 min interval between drugs administration. The reversal protocol comprised the following groups: control, KET + EOAZ100, KET + EOAZ200, KET + KET, KET + EOAZ100, KET + EOAZ200, KET + OLZ. The atypical antipsychotic OLZ was chosen as standard treatment because the ketamine-induced model of schizophrenia is more responsive to atypical antipsychotics (Becker and Grecksch 2004).

Behavioral alterations related to schizophrenia symptoms, namely positive-, negative- and cognitive symptoms, were respectively evaluated by prepulse inhibition of the startle reflex (PPI), social interaction, 
and Y-maze task, on the 14th day of treatment, 30 min after the last drug administration. Catalepsy test and body weight gain evaluated extrapyramidal side effects and weight gain and significant side effects of antipsychotic treatment.

To improve mouse performance on the behavioral tests (i.e., reduce the influence of stress by the exposure to multiple tests), one animal of each group was submitted to PPI and catalepsy tests in this order. On the other hand, distinct animals of each group were exposed to the $Y$ maze and social interaction test in this order.

We estimated the sample size of the groups used here based on the resource equation method (Charan and Kantharia, 2013). According to this method, the value " $E$ " (degree of freedom of the ANOVA) should lie between 10 and 20. In our experiments, we used 8 animals/group with 7 groups, totalizing 56 minus the number of groups 7 ; the result is 49 , which is more than the adequate number of animals.

\subsection{Behavioral determinations}

We conducted behavioral evaluations of prepulse inhibition of the startle reflex (PPI test), social interaction, and working memory by the $\mathrm{Y}$-maze task to determine positive-, negative-, and cognitive-like symptoms of schizophrenia.

PPI evaluates sensorimotor gating, an endophenotype of schizophrenia (Turetsky et al. 2007). PPI test was conducted in a startle chamber (Insight, São Paulo, Brazil), as described previously (Kinkead et al. 2006). In brief, the test was initiated with a 5 min acclimatization to the startle chamber in the presence of $65 \mathrm{~dB}$ background noise. Next, the animals received nine single $120 \mathrm{~dB}$ pulses (startle amplitude) and eighteen pulses preceded by $100 \mathrm{~ms}$ by a prepulse (PP) of 70-, 75- or $80-\mathrm{dB}$ intensity. \% PPI calculation followed the formula: \%PPI $=100$ - startle amplitude with $\mathrm{PP} \times 100$ startle amplitude of pulse alone. The results are expressed as mean \% PPI. We determined acoustic startle reactivity (ASR) by the mean amplitude of the nine trials of single pulses.

We used a Plexiglas box for the social interaction test divided into three chambers $(60 \times 40 \mathrm{~cm})$. Iron cages in each of the two side chambers contained, on one side, an unfamiliar, same-sex probe rat from the same experimental group, whereas on the other side, the cage was empty. Test animals were placed in the center chamber and allowed $5 \mathrm{~min}$ of exploration time in the box. We registered the time spent in each of the three chambers, and social preference was defined as follows: (time spent in the social chamber) - (time spent in the opposite chamber) (Radyushkin et al. 2009).

We evaluated spatial working memory by the spontaneous alternation performance in the Y-maze, which allows the evaluation of cognitive searching behavior (Maurice et al. 1996). A Y-maze apparatus made of black acrylic consisted of three arms with $425 \mathrm{~mm}$ (length), $145 \mathrm{~mm}$ (width), and $225 \mathrm{~mm}$ (height) mounted symmetrically $\left(120^{\circ}\right.$ between arms) to an equilateral triangular center compartment. Each mouse was placed at the end of one arm and freely moved through the three maze arms for 8 min. Raters blinded to the experimental groups registered the sequence of arms entries. The number of maximum alternations was the total number of arms entered minus 2 , and the percent alternation was calculated as 
(actual alternations/maximum alternations) X 100. A correct alternation is a new arm visit (example of correct alternation: 1, 2, 3 arms). An incorrect alternation is a visit to previously visited arms (example of incorrect alternation: 1, 2, 1 arms).

Side effects that emerge during the antipsychotic drug treatment, namely extrapyramidal side effects (EPSE) and weight gain, were evaluated here, respectively, by the catalepsy test and weight gain over time.

Catalepsy is the inability of an animal to correct an externally imposed posture. Catalepsy time was measured by placing each animal on a flat horizontal surface $(15 \mathrm{~cm}$ long) and $5.5 \mathrm{~cm}$ above the surface level (Costall and Naylor 1974). The total length of time that the animal stayed on the bar without any voluntary movement was recorded.

For the determination of body weight gain, the animals were weighted on the $1 \mathrm{st}$, 8th, and 14th days of each respective protocol. The body weight obtained on the 1 st day was defined as $100 \%$, and the subsequent percent of weight alterations obtained on days 8 and 14 were calculated as a percent of increase or decrease concerning the initial weight. Results are expressed as mean $\%$ alterations \pm SEM.

\subsection{Neurochemical Determinations}

After the last drug administration, hippocampal tissues were rapidly dissected, frozen, and stored at $80^{\circ} \mathrm{C}$ until assayed.

Neurochemical parameters were evaluated in the control group and animals exposed to the ketamineschizophrenia model and pretreated or post-treated with EOAZ or OLZ. The decision not to perform neurochemical analysis in the groups treated solely with EOAZ100 and EOAZ200 was to reduce the number of animals.

\subsubsection{Reduced Glutathione (GSH) Levels}

We estimated endogenous defenses against oxidative stress by GSH levels. The method is based on Ellman's reagent (DTNB) reaction, as described elsewhere (Sedlak and Lindsay 1968). For the determination of GSH levels, absorbance was set at $412 \mathrm{~nm}$. Results are expressed as $\mathrm{mg} \mathrm{GSH} / \mathrm{g}$ wet tissue.

\subsubsection{Nitrite levels}

To assess alterations in nitric oxide (NO) production, we evaluated nitrite levels in hippocampal samples. NO was determined based on the Griess reaction (Green et al. 1981; Radenovic and Selakovic 2005), with absorbance set at $550 \mathrm{~nm}$. The standard curve was prepared with several concentrations of $\mathrm{NaNO}_{2}$ (ranging from 0.75 to $100 \mu \mathrm{M}$ ). Results are expressed as $\mu \mathrm{M} / \mathrm{g}$ of protein.

\subsubsection{Immune enzymatic assay for IL-6 and BDNF}


According to the manufacturers' instructions, these parameters were determined in each sample by enzyme immunoassays (R\&D Systems, Minneapolis, MN, USA). Results are expressed as pg/g wet tissue.

\subsection{Statistical Analysis}

We used the Shapiro-Wilk test to verify the normality of the data. Repeated measures (RM) two-way ANOVA with Tukey post hoc test evaluated PPI results considering "PP intensities" (PP70, 75, and 80) as a within-groups factor and "drug treatment" (prevention and reversal groups) as a between-groups factor. For \% weight gain, we used RM two-way ANOVA with "day of treatment" as a within-subjects factor and "drug treatment" as a between-subjects factor. Social interaction, Y maze, and catalepsy time were evaluated by regular two-way ANOVA followed by Tukey post hoc test, with "treatment protocol" and "drug treatment" as factors. Neurochemical parameters were evaluated by one-way ANOVA followed by the Tukey post hoc. The significance level was set at $P \leq 0.05$. Prism 6 software ${ }^{\circledR}$ analyzed the data.

\section{Results}

\subsection{EOAZ or OLZ distinctly influence KET-induced schizophrenia-like symptoms}

In the analysis of PPI results of the prevention protocol (Fig. 2A), we observed a significant main effect of "drug treatment" $[F(6,43)=17.93, P<0.0001]$. KET repeated administration caused significant PPI deficits on PPs 70, 75, and 80 in relation to control $(P<0.0001)$. EOAZ100 $(P<0.0001)$, EOAZ200 $(P=0.0015)$, or OLZ $(P<0.0001)$ prevented KET-induced PPI deficit. Considering PPs 75 and 80, only EOAZ100 $(P<$ $0.0001)$ or OLZ $(P<0.0001)$ prevented KET-induced alterations. In the reversal protocol (Fig. $2 B)$, we observed a significant "PP intensities" vs. "drug treatment" interaction $[F(12,86)=2.099, P=0.0251]$. In this protocol, KET also caused significant PPI deficits on PPs 70, 75, and 80 compared to control $(\mathrm{P}<$ 0.0001). Post-treatment with EOAZ100, 200 or OLZ significantly reversed KET-induced PPI deficits in all PP intensities evaluated (PP70: KET vs. KET + EOAZ100, P<0.0001; KET vs. KET + EOAZ200, P = 0.0005; KET vs. KET + OLZ, P< 0.0001; PP75: KET vs. KET + EOAZ100, P<0.0001; KET vs. KET + EOAZ200, $P=$ 0.0004 ; KET vs. KET + OLZ, P < 0.0001; PP80: KET vs. KET + EOAZ100, P = 0.0057; KET vs. KET + EOAZ200, $P=0.0128 ; K E T$ vs. $K E T+O L Z, P<0.0001)$. There were no significant PPI alterations in the groups treated solely with EOAZ100 or EOAZ200 in any protocols tested.

In the evaluation of social interaction (Fig. 3A), we observed a significant "treatment protocol" vs. "drug treatment" interaction $[F(6,70)=2.602, P=0.0247]$. The post hoc analysis revealed that KET administration caused marked significant deficits in the \% of social preference in both protocols compared to control (KET vs. control: prevention protocol, $P=0.0019$; reversal protocol, $P<0.0001$ ). In the prevention protocol all treatments, EOAZ100 ( $P=0.0001), 200(P=0.0090)$ or OLZ $(P<0.0001)$ prevented KET-induced alterations. Conversely, in the reversal protocol, only OLZ significantly reversed KET-induced alterations $(P<0.0001)$. There were no significant alterations in the groups treated solely with EOAZ100 or EOAZ200. 
In the evaluation of working memory (Fig. 3B), there was a significant main effect of "drug treatment" [F $(6,85)=15.93, P<0.0001]$. In both protocols, KET-treated mice showed working memory deficits compared to control $(P<0.0001)$. In the prevention protocol, EOAZ100 maintained working memory performance like control. In contrast, both EOAZ200 and OLZ maintained KET-induced working memory deficits (control vs. OEAZ200 $+K E T, P=0.0041$; control vs. $O L Z+K E T, P<0.0001$ ). In the reversal protocol, $K E T+$ OLZ had working memory compared to the control group $(P<0.0001)$, while KET + EOAZ100 or KET + EOAZ200 presented working memory performance like control group.

\subsection{EOAZ causes fewer side effects in comparison with OLZ}

In the prevention protocol, catalepsy time increased in the groups treated with EOAZ200 alone or EOAZ200 + KET, while a marked 25-fold increase was observed in OLZ + KET when compared to control $(P<0.0001)$. EOAZ200, KET + EOAZ100, or KET + EOAZ200 incremented catalepsy time compared to control $(P<0.0001)$ in the reversal protocol. Again, KET + OLZ induced a higher catalepsy time (24-fold increase) when compared to control ("treatment protocol" vs. "drug treatment" interaction $[F(6,71)=$ 24.15, $P<0.0001$ ] (Fig. 4A).

Regarding weight gain, in the prevention protocol (Fig. 4B), we observed a significant main effect of "day of treatment" $[F(1,42)=9.528, P=0.0036]$ and "drug treatment" $[F(6,42)=29.48, P<0.0001]$. On days 8 and 14, the groups EOAZ100 + KET or OLZ + KET had significant weight gain compared to control. Furthermore, $\mathrm{OLZ}+\mathrm{KET}$ presented a progressive increase in weight gain from day 8 to day $14(P<0.001)$. In the reversal protocol (Fig. 4C), weight gain was significantly higher, on day 8, in KET + SAL, KET + EOAZ100, or KET + OLZ groups compared to control. On day 14, this increase was observed in the KET or KET + OLZ group. Notably, KET or KET + OLZ presented progressive increase in weight gain, while the opposite was observed in KET + EOAZ100 from days 8 to 14 ("day of treatment" vs. "drug treatment" interaction $[F(6,42)=11.17, P<0.0001]$, main effect of "day of treatment" $[F(1,42)=5.510, P=0.0237]$, main effect of "drug treatment" $[F(6,42)=10.83$, $P<0.0001]$.

\subsection{EOAZ or OLZ distinctly influence KET-induced hippocampal oxidative, neuroinflammatory, and neurotrophic alterations}

As depicted in Fig. 5A, we observed a significant interaction between "treatment protocol" vs. "drug treatment" in the analysis of GSH hippocampal levels $[F(4,53)=36.89, P<0.0001]$. Tukey test revealed a significant decrease in GSH levels in KET-treated mice from both prevention and reversal protocols compared to control $(\mathrm{P}<0.0001)$. In the prevention protocol, only OLZ pretreatment significantly prevented GSH deficits induced by KET $(P<0.0001)$. Conversely, pretreatment with EOAZ100 or EOAZ200 maintained GSH deficits induced by KET ( $P<0.0001$, when compared to control). In the reversal protocol, post-treatment with EOAZ100, EOAZ200, or OLZ significantly reversed the decrease in GSH levels induced by KET $(P<0.0001)$. 
In the evaluation of hippocampal nitrite levels (Fig. 5B), there was also a significant "treatment protocol" vs. "drug treatment" interaction $[F(4,60)=15.53, P<0.0001]$. Tukey's test revealed a marked 5 -fold increase in nitrite levels in the KET-treated group from reversal protocol in relation to control $(P<0.0001)$. All treatments significantly reversed this KET-induced alteration in nitrite levels $(P<0.0001)$. We observed no hippocampal changes in nitrite levels in mice subjected to the prevention protocol.

Interleukin 6 levels (Fig. 6A) significantly increased after KET administration in both protocols when compared to control animals $(P<0.0001)$. Only EOAZ200 + KET maintained IL-6 levels like those of control (EOAZ200 + KET vs. KET, P < 0.0001). Conversely, EOAZ100 + KET, or OLZ + KET, despite causing a significant decrease in IL-6 levels when compared to KET $(P<0.01)$, had increased levels of IL- 6 when compared to control $(P<0.0001)$. In the reversal protocol, both doses of EOAZ reversed the increase in IL6 induced by KET $(P<0.0001)$. KET + OLZ group had a slight and significant decrease in IL-6 levels when compared to KET $(P<0.05)$, although significantly higher than control group $(P<0.0001)$ (One-way ANOVA - prevention protocol $[F(4,25)=44.57, P<0.0001]$; reversal protocol $[F(4,29)=88.14, P<0.0001]$.

Considering BDNF levels, in the prevention protocol, we observed decreased levels of this neurotrophin in the groups' KET, EOAZ200 + KET, or OLZ + KET when compared to control $(P<0.0001)$. Despite presenting decreased levels of BDNF when compared to control, the EOAZ100 + KET group had increased levels of this neurotrophin in relation to KET $(P<0.05)$ (One-way ANOVA: $[F(4,27)=55.28, P<0.0001])$. In the reversal protocol, the levels of BDNF were decreased in all groups in relation to control $(P<0.001)$. Nevertheless, KET + EOAZ100 or KET + OLZ groups presented increased BDNF when compared to KET ( $P$ $<0.0001$ ) (One-way ANOVA: $[F(4,30)=31.77, \mathrm{P}<0.0001]$.

\section{Discussion}

Here we add novel evidence for EOAZ antipsychotic effects by showing that it prevents and reverses behavioral alterations induced by KET repeated administration in mice that resemble schizophrenia symptoms by anti-inflammatory, antioxidant, and neurotrophic mechanisms. We also showed that the oil's effects are quite like those of the atypical antipsychotic OLZ but devoid of some important side effects observed in antipsychotic drug therapy, namely weight gain and catalepsy. Notably, only EOAZ, but not OLZ, prevented and reversed working memory deficits and turned KET-induced IL- 6 increments to control levels. Hence, EOAZ seems to be a promising drug therapy for schizophrenia or a source of new compounds for investigation against this devasting disease.

Herbal and plant-derived medicines are recognized for their beneficial therapeutic effects with few adverse effects (Edris 2007; Kennedy and Wightman 2011). Regarding schizophrenia, some plant extracts presented promising efficacy in preclinical and some preliminary human trials, such as Melissa officinalis L (Melissa or Lemon balm) and Valeriana officinalis L (Valerian) (Rahmatullah et al. 2010; Ahmed and Kabidul Azam 2014; Dey et al. 2016).

We have previously demonstrated the efficacy of the EOAZ in preventing hyperlocomotion induced by a single KET dose in mice. In this previous study, $200 \mathrm{mg} / \mathrm{kg}$ EOAZ induced sedative effects with no motor 
coordination impairment (De Araújo et al., 2011). Importantly, KET single administration causes psychotic alterations that resemble only positive symptoms of schizophrenia but not the syndrome (Chatterjee et al. 2011).

We used repeated KET administration to induce broader behavioral changes that simulate positive, negative, and cognitive symptoms of schizophrenia (Chatterjee et al. 2011). The KET model presents a relevant face, construct, and predictive validity (Monte et al. 2013c; Frohlich and Van Horn 2014).

PPI is a neurophysiological endophenotype of schizophrenia, reflecting the ability to regulate sensory information (Braff and Light 2005). PPI is disrupted in mice repeatedly exposed to KET (Monte et al., 2013), and attenuated by atypical antipsychotics (risperidone and clozapine) (Vasconcelos et al., 2015).

Our results revealed that EOAZ, quite like OLZ, prevented and reversed PPI deficits induced by KET in both doses tested, but most efficiently at $100 \mathrm{mg} / \mathrm{kg}$. These findings corroborated our previous evidence about EAOZ effects against schizophrenia-like psychotic symptoms in rodents (De Araújo et al. 2009, 2011).

Cognitive deterioration is another major breakpoint of schizophrenia psychopathology. Combined with negative symptoms (for example, asociality, avolition, and anhedonia), are the major causes of functional impairment and morbidity of this disorder (Bowie and Harvey 2006). Notably, current antipsychotic drugs present a limited effect against negative and cognitive symptoms of schizophrenia (Burton 2006).

Here, EOAZ successfully prevented the emergence of social deficits induced by KET, i.e., prevented the emergence of negative symptoms. On the other hand, OLZ prevented and reversed sociability changes induced by this model.

Although initial reports have pointed to some advantages of atypical antipsychotics for treating cognitive symptoms, subsequent studies failed to significantly benefit these agents for cognition (Meltzer et al. 1999; Cuesta et al. 2001). Therefore, therapeutic strategies for working memory deficits in schizophrenia are demanding and of great interest.

Ketamine caused a marked working memory impairment in mice, which was not affected by OLZ. EOAZ $100 \mathrm{mg} / \mathrm{kg}$ had a modest effect in improving this cognitive alteration in both prevention and reversal protocols. To our knowledge, our results bring the first evidence about EAOZ pro-cognitive effects in schizophrenia, which, despite the promising potential, should be confirmed by further studies evaluating other tasks and cognitive domains, such as attention, cognitive flexibility, and reference memory.

Catalepsy test evaluates drug-induced EPSE in mice (Gobira et al. 2013). Both typical and atypical antipsychotics can induce catalepsy (Kapur et al. 2000). We observed that OLZ, in both prevention and reversal protocols, induced a marked cataleptic effect. In the prevention protocol, EOAZ 100 $\mathrm{mg} / \mathrm{kg}$ caused no cataleptic alteration. In the reversal protocol, EOAZ increased catalepsy time in mice. EOAZ at the higher dose also increased catalepsy time in control conditions, which may be associated with the oil's antagonistic dopamine activity (De Araújo et al. 2009). These results suggest that the oil presents less potential to cause adverse EPSE than OLZ. 
In our protocol, as expected, OLZ caused a considerable weight gain in both prevention and reversal treatments. Conversely, EOAZ caused no critical alterations in weight gain, mainly at a dose of 200 $\mathrm{mg} / \mathrm{kg}$. Atypical antipsychotics have severe metabolic effects, being weight gain the most common of them. Antipsychotic-induced weight gain is also frequently accompanied by hypertension, insulin resistance, and hypertriglyceridemia (Elmslie et al. 2009). Olanzapine and clozapine are the antipsychotics associated with the highest amount of weight gain (Elmslie et al. 2009). Notably, EOAZ presents antihypertensive and antiatherogenic properties (Bezerra et al. 2000; Lahlou et al. 2002; De Araújo Pinho et al. 2005; Chompoo et al. 2012).

Lieberman and coworkers (2018) proposed a unifying theory for hippocampal changes in the evolution of schizophrenia (Lieberman et al. 2018). Briefly, genetic and/or environmental factors promote dysregulation of glutamatergic neurotransmission beginning in the Cornus ammonis (CA) 1 region related to prodromal symptoms and initiation of psychosis. As the illness progresses, this pathological process expands to other regions of the hippocampal circuit and projects to other anatomic areas causing hippocampal neuropil and interneurons atrophy (Lieberman et al. 2018), another relevant alteration observed in schizophrenia (Osimo et al. 2019).

An altered redox state is a well-known neurobiological feature of schizophrenia (Bošković et al. 2011). Oxidative stress seems to be an initial and final/secondary mechanism important to mediate neurodegeneration after several injury factors, such as neuroinflammation, glutamatergic dysfunction, and dopamine imbalance (Bitanihirwe and WOO 2011). In this context, atypical antipsychotics present marked antioxidant actions (Monte et al. 2013c, 2020).

Here, EOAZ, mainly at $200 \mathrm{mg} / \mathrm{kg}$, successfully reversed the hippocampal depletion of endogenous GSH and increased nitrite levels caused by the KET model. Similarly, OLZ protected mice hippocampus against pro-oxidative changes.

Interleukin-6 is the major cytokine in the central nervous system, being altered in major psychiatric disorders (Erta et al. 2012). Chronic schizophrenic patients present increased levels of IL-6 in the cerebrospinal fluid (CSF) (Schwieler et al. 2015). Furthermore, a single IL-6 injection during pregnancy causes schizophrenia-like behavioral abnormalities in wild-type mice, but not in IL-6 knockout mice (Smith et al. 2007). Together, these data posit IL-6 relevance for schizophrenia neurobiology.

We have previously shown that the KET model increased hippocampal IL-6 levels, followed by increased levels of other pro-inflammatory and pro-oxidative markers (lipid peroxidation, MPO activity, nitrosative stress) (Araújo et al. 2016). Here, we replicated our previous results showing a KET-induced marked rise in hippocampal IL-6 in both prevention and reversal protocols, which EOAZ efficiently counteracted. Notably, the effect of the oil was superior to OLZ.

Oxidative imbalance and immune disturbances compromise synaptic plasticity, causing neurodegeneration in schizophrenia. BDNF is a crucial mediator of differentiation, survival, and plasticity of several different neurons' populations (Zagrebelsky and Korte 2014). In schizophrenia, a robust meta- 
analysis described moderately reduced peripheral BDNF levels in the serum and plasma of patients and recovered levels after antipsychotic therapy (Fernandes et al. 2011). In the KET model, mice seem to present reduced hippocampal BDNF (Fraga et al. 2013; Vasconcelos et al. 2015). However, another study also showed that repeated KET administration in mice did not cause any significant difference in brain BDNF expression (Gama et al. 2012). However, different KET doses used in these studies, protocol duration, animal age, and BDNF detection method (gene expression vs. protein detection) can explain these discrepancies.

In our results, the KET model caused a consistent reduction in hippocampal BDNF expression in both prevention and reversal protocols. EOAZ $100 \mathrm{mg} / \mathrm{kg}$ in both protocols significantly increased BDNF levels more efficiently than OLZ. Some constituents of EOAZ, namely 1,8-cineole, terpinene-4-ol, and caryophyllene, present neuroactive and neuroprotective properties. 1,8-cineole, also known as eucalyptol or cajeputol, is a monoterpene ether is present in many plant essential oils, known as eucalyptol or cajeputol. 1,8-cineole alters neural firing in the olfactory lobe and has antinociceptive action (Liapi et al. 2007). Terpinene-4-ol, in turn, showed CNS depressant and anticonvulsant activity in mice (Nóbrega et al. 2014; Sousa et al. 2015).

Caryophyllene is a phytocannabinoid with cannabinoid receptor type 2 (CB-2) agonist properties. Caryophyllene presents antinociceptive, anxiolytic, and antidepressant effects (Bahi et al. 2014; Aly et al. 2020; Hwang et al. 2020). Additionally, there is an ongoing clinical trial with beta-caryophyllene for schizophrenia treatment (application $\mathrm{N}^{\circ} \mathrm{EP} 13763464.8 \mathrm{~A}$ ). These phytochemicals alone or combined can be responsible for EAOZ promising effect seen here but needs further evaluation.

\section{Conclusions}

Our results reveal the promising anti-schizophrenia action of the EOAZ. EOAZ counteracted the most behavioral alterations resembling schizophrenia symptoms induced by KET, with a more favorable side effect profile than the standard antipsychotic OLZ. Also, EOAZ protected mice hippocampus against the most KET-induced pro-oxidative changes and restored BDNF contents. Together, these findings provide broader preclinical evidence about using this plant oil as a valuable new therapeutic strategy for schizophrenia.

\section{Declarations}

\section{Role of funding source}

Brazilian Institutions, CNPq, CAPES, and FUNCAP partially funded this study.

\section{Conflict of interests}

The authors declare no conflict of interests 


\section{Acknowledgment}

We thank the Brazilian Institutions, CNPq, CAPES, and FUNCAP for the financial

support of this study.

\section{Data Availability}

Data will be made available under request

\section{Authors' Contributions}

FYRA, DFL, MOM, MEM - Designed the study

AJMCF, AMN, GVO, PXLG - treated the animals and performed behavioral tests

GSV, AJMCF, JC - Performed neurochemical determinations

DFL, DSM, FCFS - Performed statistical analysis of the data

DFL, DSM - constructed the graphics

FYRA, DSM, JC, AJMCF - Wrote the first draft of the manuscript

All authors approved the final version of the manuscript

\section{References}

Adams R (2009) Identification of Essential oil components by gas Chromatography / Quadrupole Mass Spectroscopy. 459

Ahmed MN, Kabidul Azam MN (2014) Traditional Knowledge and Formulations of Medicinal Plants Used by the Traditional Medical Practitioners of Bangladesh to Treat Schizophrenia Like Psychosis. Schizophr Res Treatment 2014:1-10. https://doi.org/10.1155/2014/679810

Aly E, Khajah MA, Masocha W (2020) $\beta$-caryophyllene, a CB2-receptor-selective phytocannabinoid, suppresses mechanical allodynia in a mouse model of antiretroviral-induced neuropathic pain. Molecules 25:. https://doi.org/10.3390/molecules25010106

Araújo S, Jose A, Chaves M, et al (2016) Reversal of schizophrenia-like symptoms and immune alterations in mice by immunomodulatory drugs. J Psychiatr Res.

https://doi.org/10.1016/j.jpsychires.2016.09.017

Bahi A, Al Mansouri S, Al Memari E, et al (2014) $\beta$-Caryophyllene, a CB2 receptor agonist produces multiple behavioral changes relevant to anxiety and depression in mice. Physiol Behav 135:119-124. https://doi.org/10.1016/j.physbeh.2014.06.003 
Becker A, Grecksch G (2004) Ketamine-induced changes in rat behaviour: a possible animal model of schizophrenia. Test of predictive validity. Prog Neuropsychopharmacol Biol Psychiatry 28:1267-77. https://doi.org/10.1016/j.pnpbp.2004.06.019

Bezerra MAC, Leal-Cardoso JH, Coelho-de-Souza AN, et al (2000) Myorelaxant and antispasmodic effects of the essential oil of Alpinia speciosa on rat ileum. Phyther Res 14:549-551.

https://doi.org/10.1002/1099-1573(200011)14:7<549::AID-PTR623>3.0.CO;2-T

Bitanihirwe BKY, WOO TUW (2011) Oxidative stress in schizophrenia: An integrated approach

Bošković M, Vovk TT, Kores Plesničar B, et al (2011) Oxidative stress in schizophrenia. Curr Neuropharmacol 9:301-12. https://doi.org/10.2174/157015911795596595

Bowie CR, Harvey PD (2006) Cognitive deficits and functional outcome in schizophrenia. Neuropsychiatr. Dis. Treat. 2:531-536

Braff DL, Light GA (2005) The use of neurophysiological endophenotypes to understand the genetic basis of schizophrenia. Dialogues Clin Neurosci 7:125-35

Burton S (2006) Symptom domains of schizophrenia: the role of atypical antipsychotic agents. J Psychopharmacol 20:6-19. https://doi.org/10.1177/1359786806071237

Campbell M, Young PI, Bateman DN, et al (1999) The use of atypical antipsychotics in the management of schizophrenia. Br J Clin Pharmacol 47:13-22. https://doi.org/10.1046/j.1365-2125.1999.00849.x

Carpenter WT, Davis JM (2012) Another view of the history of antipsychotic drug discovery and development. Mol Psychiatry 17:1168-1173. https://doi.org/10.1038/mp.2012.121

Chatterjee M, Ganguly S, Srivastava M, Palit G (2011) Effect of "chronic" versus "acute" ketamine administration and its "withdrawal" effect on behavioural alterations in mice: Implications for experimental psychosis. Behav Brain Res 216:247-254. https://doi.org/10.1016/j.bbr.2010.08.001

Chompoo J, Upadhyay A, Gima S, et al (2012) Antiatherogenic properties of acetone extract of Alpinia zerumbet seeds. Molecules. https://doi.org/10.3390/molecules17066249

Costall B, Naylor RJ (1974) On catalepsy and catatonia and the predictability of the catalepsy test for neuroleptic activity. Psychopharmacologia 34:233-241

Craveiro AA, Matos FJA, de Alencar JW (1976) A simple and inexpensive steam generator for essential oils extraction. J Chem Educ 53:652. https://doi.org/10.1021/ed053p652

Cuesta MJ, Peralta V, Zarzuela A (2001) Effects of olanzapine and other antipsychotics on cognitive function in chronic schizophrenia: A longitudinal study. Schizophr Res 48:17-28.

https://doi.org/10.1016/S0920-9964(00)00112-2 
da Silva Araújo T, Maia Chaves Filho AJ, Monte AS, et al (2017) Reversal of schizophrenia-like symptoms and immune alterations in mice by immunomodulatory drugs. J Psychiatr Res 84 :.

https://doi.org/10.1016/j.jpsychires.2016.09.017

De Araújo FYR, De Oliveira GV, Gomes PXL, et al (2011) Inhibition of ketamine-induced hyperlocomotion in mice by the essential oil of Alpinia zerumbet: Possible involvement of an antioxidant effect. J Pharm Pharmacol 63:1103-1110. https://doi.org/10.1111/j.2042-7158.2011.01312.x

De Araújo FYR, Silva MIG, Moura BA, et al (2009) Central nervous system effects of the essential oil of the leaves of Alpinia zerumbet in mice. J Pharm Pharmacol 61:. https://doi.org/10.1211/jpp/61.11.0012

de Araújo FYRFYR, Silva MIGMIG, Moura BABA, et al (2009) Central nervous system effects of the essential oil of the leaves of Alpinia zerumbet in mice. J Pharm Pharmacol 61:1521-7. https://doi.org/10.1211/jpp/61.11.0012

De Araújo Pinho FVS, Coelho-De-Souza AN, Morais SM, et al (2005) Antinociceptive effects of the essential oil of Alpinia zerumbet on mice. Phytomedicine 12:482-486.

https://doi.org/10.1016/j.phymed.2004.04.006

Dey A, Das S, Mukherjee A (2016) Possible natural therapeutics against schizophrenia and its acute and treatment resistant forms: a review. J Biol Act Prod from Nat 6:1-24.

https://doi.org/10.1080/22311866.2016.1175318

Edris AE (2007) Pharmaceutical and therapeutic potentials of essential oils and their individual volatile constituents: A review. Phyther. Res. 21:308-323

Elmslie JL, Porter RJ, Joyce PR, et al (2009) Comparison of Insulin Resistance, Metabolic Syndrome and Adiponectin in Overweight Bipolar Patients Taking Sodium Valproate and Controls. Aust New Zeal J Psychiatry 43:53-60. https://doi.org/10.1080/00048670802534341

Erta M, Quintana A, Hidalgo J (2012) Interleukin-6, a Major Cytokine in the Central Nervous System. Int J Biol Sci 8:1254-1266. https://doi.org/10.7150/ijbs.4679

Favalli G, Li J, Belmonte-de-Abreu P, et al (2012) The role of BDNF in the pathophysiology and treatment of schizophrenia. J Psychiatr Res 46:1-11. https://doi.org/10.1016/j.jpsychires.2011.09.022

Fernandes BSSS, Gama CS, Maria Ceres??r K, et al (2011) Brain-derived neurotrophic factor as a statemarker of mood episodes in bipolar disorders: A systematic review and meta-regression analysis. $\mathrm{J}$ Psychiatr Res 45:995-1004. https://doi.org/10.1016/j.jpsychires.2011.03.002

Fraga DB, Réus GZ, Abelaira HM, et al (2013) Ketamine alters behavior and decreases BDNF levels in the rat brain as a function of time after drug administration. Rev Bras Psiquiatr 35:262-266.

https://doi.org/10.1590/1516-4446-2012-0858 
Frohlich J, Van Horn JD (2014) Reviewing the ketamine model for schizophrenia. J Psychopharmacol 28:287-302. https://doi.org/10.1177/0269881113512909

Gaebel W, Stricker J, Riesbeck M (2019) The long-term antipsychotic treatment of schizophrenia: A selective review of clinical guidelines and clinical case examples. Schizophr Res.

https://doi.org/https://doi.org/10.1016/j.schres.2019.10.049

Gama CS, Canever L, Panizzutti B, et al (2012) Effects of omega-3 dietary supplement in prevention of positive, negative and cognitive symptoms: a study in adolescent rats with ketamine-induced model of schizophrenia. Schizophr Res 141:162-7. https://doi.org/10.1016/j.schres.2012.08.002

Gobira PH, Ropke J, Aguiar DC, et al (2013) Animal models for predicting the efficacy and side effects of antipsychotic drugs. Rev Bras Psiquiatr 35:S132-S139. https://doi.org/10.1590/1516-4446-2013-1164

Green LC, Goldman P, Tannenbaum SR, Goldman P (1981) Nitrate synthesis in the germfree and conventional rat. Science (80- ) 212:56-58. https://doi.org/10.1126/science.6451927

Harrison P (2004) The hippocampus in schizophrenia: a review of the neuropathological evidence and its pathophysiological implications. Psychopharmacology (Berl) 174:151-62.

https://doi.org/10.1007/s00213-003-1761-y

Howes O, McCutcheon R, Stone J (2015) Glutamate and dopamine in schizophrenia: an update for the 21st century. J Psychopharmacol 29:97-115. https://doi.org/10.1177/0269881114563634

Hwang ES, Kim HB, Lee S, et al (2020) Antidepressant-like effects of $\beta$-caryophyllene on restraint plus stress-induced depression. Behav Brain Res 380:. https://doi.org/10.1016/j.bbr.2019.112439

Irifune M, Shimizu T, Nomoto M (1991) Ketamine-induced hyperlocomotion associated with alteration of presynaptic components of dopamine neurons in the nucleus accumbens of mice. Pharmacol Biochem Behav 40:399-407. https://doi.org/10.1016/0091-3057(91)90571-I

Javitt DC, Zukin SR, Heresco-Levy U, Umbricht D (2012) Has an angel shown the way? Etiological and therapeutic implications of the PCP/NMDA model of schizophrenia. Schizophr Bull 38:958-966. https://doi.org/10.1093/schbul/sbs069

Kapur S, Zipursky R, Jones C, et al (2000) Relationship between dopamine D2 occupancy, clinical response, and side effects: A double-blind PET study of first-episode schizophrenia. Am J Psychiatry. https://doi.org/10.1176/appi.ajp.157.4.514

Kennedy DO, Wightman EL (2011) Herbal extracts and phytochemicals: plant secondary metabolites and the enhancement of human brain function. Adv Nutr 2:32-50. https://doi.org/10.3945/an.110.000117

Kinkead B, Selz KA, Owens MJ, Mandell AJ (2006) Algorithmically designed peptides ameliorate behavioral defects in animal model of ADHD by an allosteric mechanism. J Neurosci Methods 151:68- 
Lahlou S, Galindo CAB, Leal-Cardoso JH, et al (2002) Cardiovascular effects of the essential oil of Alpinia zerumbet leaves and its main constituent, terpinen-4-ol, in rats: Role of the autonomic nervous system. Planta Med 68:1097-1102. https://doi.org/10.1055/s-2002-36336

Li P, Snyder GL, Vanover KE (2016) Dopamine Targeting Drugs for the Treatment of Schizophrenia: Past, Present and Future. Curr Top Med Chem 16:3385-3403. https://doi.org/10.2174/1568026616666160608084834

Liapi C, Anifantis G, Chinou I, et al (2007) Antinociceptive properties of 1,8-cineole and $\beta$-pinene, from the essential oil of Eucalyptus camaldu lensis leaves, in rodents. Planta Med 73:1247-1254. https://doi.org/10.1055/s-2007-990224

Lieberman JA, Girgis RR, Brucato G, et al (2018) Hippocampal dysfunction in the pathophysiology of schizophrenia: a selective review and hypothesis for early detection and intervention. Mol Psychiatry 23:1764-1772. https://doi.org/10.1038/mp.2017.249

Maurice T, Lockhart BP, Privat A (1996) Amnesia induced in mice by centrally administered beta-amyloid peptides involves cholinergic dysfunction. Brain Res 706:181-93

Meltzer HY, Park S, Kessler R (1999) Cognition, schizophrenia, and the atypical antipsychotic drugs. Proc. Natl. Acad. Sci. U. S. A. 96:13591-13593

Monte a. S, de Souza GC, Mclntyre RS, et al (2013a) Prevention and reversal of ketamine-induced schizophrenia related behavior by minocycline in mice: Possible involvement of antioxidant and nitrergic pathways. J Psychopharmacol 27:1032-1043. https://doi.org/10.1177/0269881113503506

Monte AS, De Souza GC, Mclntyre RS, et al (2013b) Prevention and reversal of ketamine-induced schizophrenia related behavior by minocycline in mice: Possible involvement of antioxidant and nitrergic pathways. J Psychopharmacol 27:. https://doi.org/10.1177/0269881113503506

Monte ASAS, da Silva FERFER, Lima CNDCCN de C, et al (2020) Sex influences in the preventive effects of N-acetylcysteine in a two-hit animal model of schizophrenia. J Psychopharmacol 34:125-136. https://doi.org/10.1177/0269881119875979

Monte ASSAS, De Souza GCGCC, Mclntyre RSRSS, et al (2013c) Prevention and reversal of ketamineinduced schizophrenia related behavior by minocycline in mice: Possible involvement of antioxidant and nitrergic pathways. J Psychopharmacol 27:1032-1043. https://doi.org/10.1177/0269881113503506

Muller N, Schwarz M (2006) Schizophrenia as an inflammation-mediated dysbalance of glutamatergic neurotransmission. Neurotox Res 10:131-48 
$\mathrm{NIH}$ (1996) Guide for the Care and Use of Laboratory Animals- Institute of Laboratory Animal ResearchNational Research Council. Natl Acad Press

Nóbrega FFF, Salvadori MGSS, Masson CJ, et al (2014) Monoterpenoid Terpinen-4-ol Exhibits Anticonvulsant Activity in Behavioural and Electrophysiological Studies. Oxid Med Cell Longev 2014:. https://doi.org/10.1155/2014/703848

Osimo EF, Beck K, Reis Marques T, Howes OD (2019) Synaptic loss in schizophrenia: a meta-analysis and systematic review of synaptic protein and mRNA measures. Mol Psychiatry 24:549-561. https://doi.org/10.1038/s41380-018-0041-5

Radenovic L, Selakovic V (2005) Differential effects of NMDA and AMPA/kainate receptor antagonists on nitric oxide production in rat brain following intrahippocampal injection. Brain Res Bull 67:133-41. https://doi.org/10.1016/j.brainresbull.2005.06.019

Radyushkin K, Hammerschmidt K, Boretius S, et al (2009) Neuroligin-3-deficient mice: model of a monogenic heritable form of autism with an olfactory deficit. Genes Brain Behav 8:416-425. https://doi.org/10.1111/j.1601-183X.2009.00487.x

Rahmatullah M, Rahman MA, Hossan MS, et al (2010) A pharmacological and phytochemical evaluation of medicinal plants used by the Harbang clan of the Tripura tribal community of Mirsharai area, Chittagong district, Bangladesh. J Altern Complement Med 16:769-85.

https://doi.org/10.1089/acm.2009.0497

Reagan-Shaw S, Nihal M, Ahmad N (2008) Dose translation from animal to human studies revisited. FASEB J 22:659-61. https://doi.org/10.1096/fj.07-9574LSF

Satou T, Kasuya H, Takahashi M, et al (2011) Relationship between duration of exposure and anxiolyticlike effects of essential oil from Alpinia zerumbet. Flavour Fragr J. https://doi.org/10.1002/ffj.2047

Satou T, Murakami S, Matsuura M, et al (2010) Anxiolytic effect and tissue distribution of inhaled Alpinia zerumbet essential oil in mice. Nat Prod Commun. https://doi.org/10.1177/1934578x1000500133

Schwieler L, Larsson MK, Skogh E, et al (2015) Increased levels of IL-6 in the cerebrospinal fluid of patients with chronic schizophrenia--significance for activation of the kynurenine pathway. J Psychiatry Neurosci 40:126-33

Sedlak J, Lindsay RH (1968) Estimation of total, protein-bound, and nonprotein sulfhydryl groups in tissue with Ellman's reagent. Anal Biochem 25:192-205. https://doi.org/10.1016/0003-2697(68)90092-4

Smith SEP, Li J, Garbett K, et al (2007) Maternal immune activation alters fetal brain development through interleukin-6. J Neurosci 27:10695-702. https://doi.org/10.1523/JNEUROSCI.2178-07.2007 
Sousa DP de, Nóbrega FFF, Morais LCSL de, Almeida RN de (2015) Evaluation of the Anticonvulsant Activity of Terpinen-4-ol. Zeitschrift für Naturforsch C 64:1-5. https://doi.org/10.1515/znc-2009-1-201

Tan S, Lam WP, Wai MSM, et al (2012) Chronic Ketamine Administration Modulates Midbrain Dopamine System in Mice. PLoS One 7:e43947. https://doi.org/10.1371/journal.pone.0043947

Tu PTB, Tawata S (2015) Anti-oxidant, anti-aging, and anti-melanogenic properties of the essential oils from two varieties of Alpinia zerumbet. Molecules 20:16723-16740.

https://doi.org/10.3390/molecules200916723

Turetsky BI, Calkins ME, Light GA, et al (2007) Neurophysiological endophenotypes of schizophrenia: the viability of selected candidate measures. Schizophr Bull 33:69-94.

https://doi.org/10.1093/schbul/sbl060

Vasconcelos GSGS, Ximenes NCNC, de Sousa CNSCNS, et al (2015) Alpha-lipoic acid alone and combined with clozapine reverses schizophrenia-like symptoms induced by ketamine in mice:

Participation of antioxidant, nitrergic and neurotrophic mechanisms. Schizophr Res 165:163-70. https://doi.org/10.1016/j.schres.2015.04.017

Zagrebelsky M, Korte M (2014) Form follows function: BDNF and its involvement in sculpting the function and structure of synapses. Neuropharmacology 76:628-638.

https://doi.org/10.1016/j.neuropharm.2013.05.029

\section{Figures}




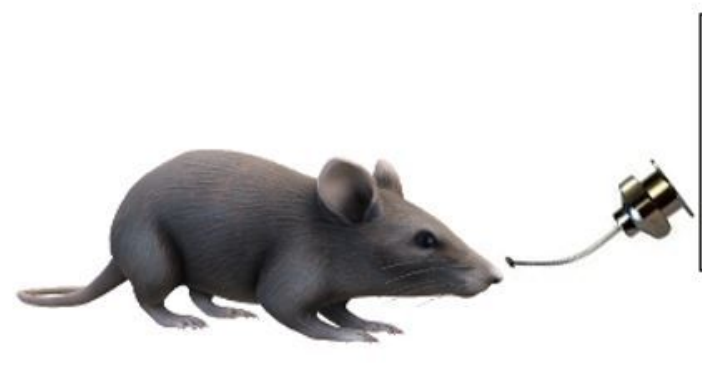

\section{Antipsychotic Strategies}

EOAZ 100 or $200 \mathrm{mg} / \mathrm{kg}$ (tested compound) Olanzapine $2 \mathrm{mg} / \mathrm{kg}$ (standard drug)
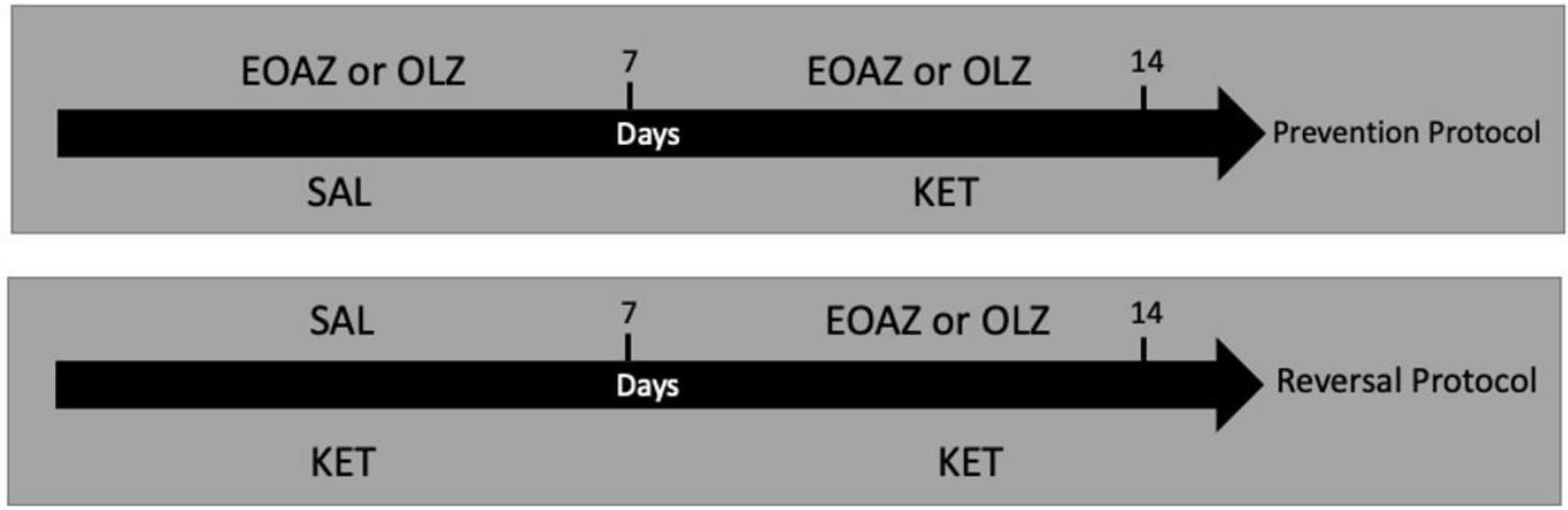

\section{Figure 1}

Schematic representation of the experimental design. In the prevention protocol, from the $1 \mathrm{st}$ to the 7thday, mice received daily oral administrations of EOAZ 100, $200 \mathrm{mg} / \mathrm{kg}$, or OLZ $2 \mathrm{mg} / \mathrm{kg}$, while from the 8th to 14th days further received intraperitoneal injections of KET $20 \mathrm{mg} / \mathrm{kg}$. In the reversal protocol, from the $1 \mathrm{st}$ to the 7th-day, the animals received intraperitoneal injections of KET $20 \mathrm{mg} / \mathrm{kg}$, while from the 8th to the 14th-day, they were further treated with EOAZ 100, $200 \mathrm{mg} / \mathrm{kg}$, or OLZ $2 \mathrm{mg} / \mathrm{kg}$. Abbreviations: EOAZ - essential oil of Alpinia zerumbet; OLZ - olanzapine; KET - ketamine. 


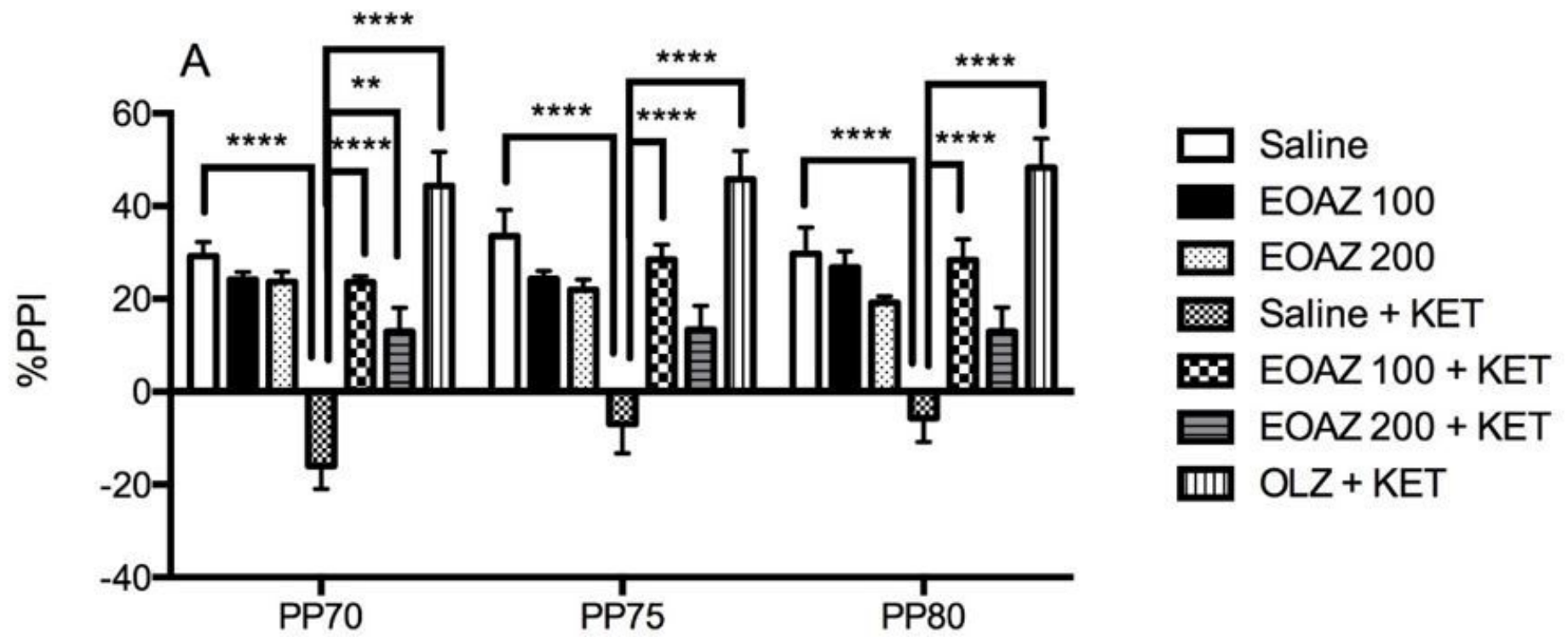

Reversal

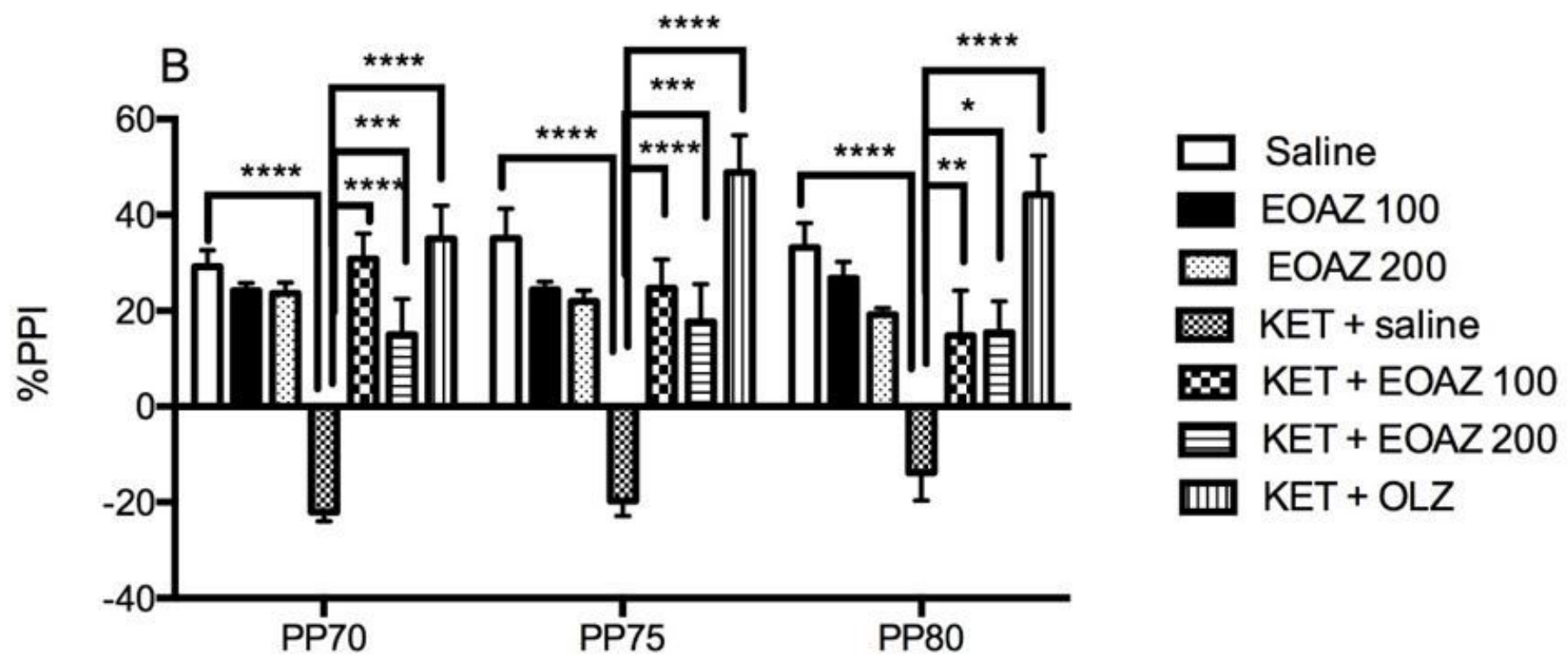

Figure 2

Effect of EOAZ on KET-induced PPI deficits. Mice were treated with the essential oil from Alpinia zerumbet (EOAZ 50, 100, and $200 \mathrm{mg} / \mathrm{kg}$, p.o.) or $2 \mathrm{mg} / \mathrm{kg}$ olanzapine in the prevention (A) and reversal (B) protocols of KET- schizophrenia model. Bars represent mean \pm SEM of the percent of PPI $(n=8$ animals/group). ${ }^{\star} \mathrm{P}<0.05,{ }^{\star *} \mathrm{P}<0.01,{ }^{\star \star *} \mathrm{P}<0.001,{ }^{* \star \star *} \mathrm{P}<0.0001$ according to two-way ANOVA followed by 
Turkey's post-hoc test. Abbreviations: EOAZ: essential oil of Alpinia zerumbet; KET: ketamine; OLZ: olanzapine; PPI: prepulse inhibition.

Social interaction

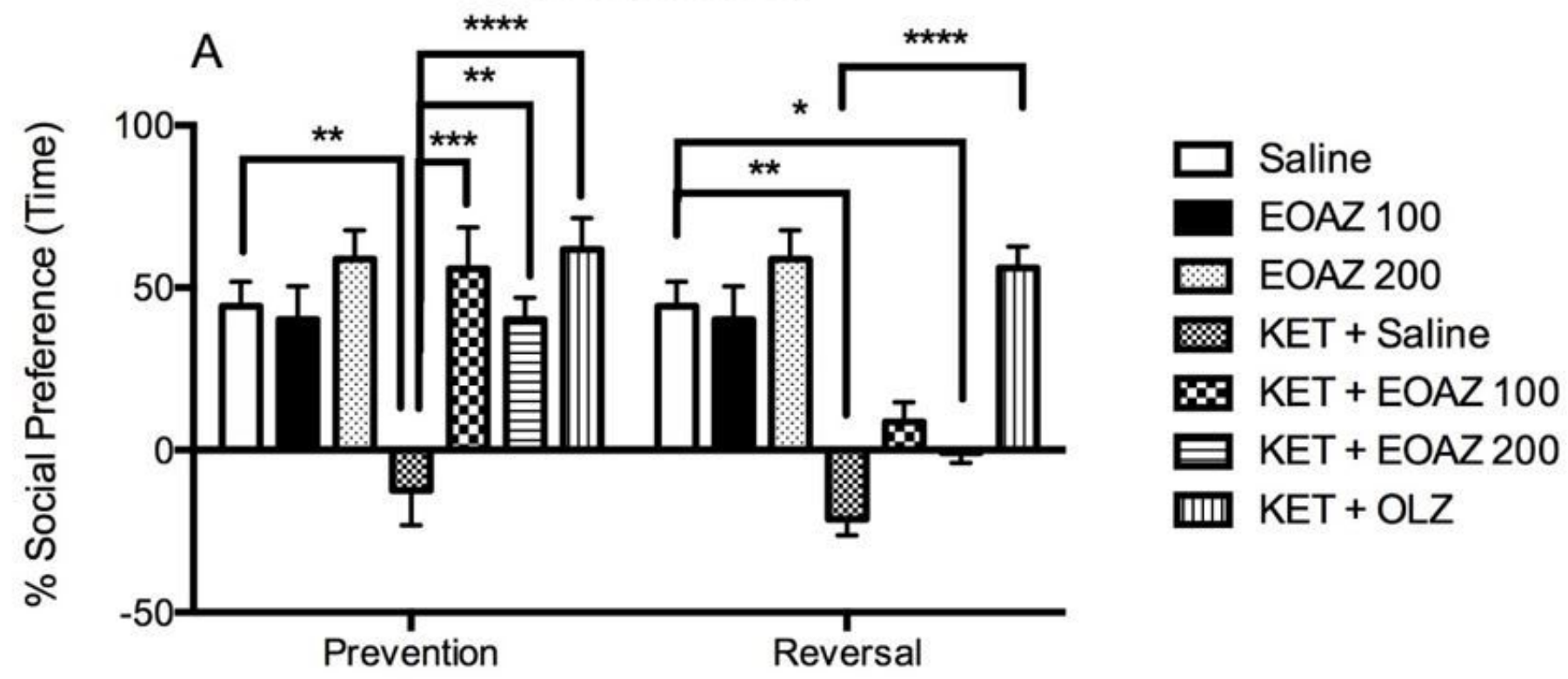

Y maze

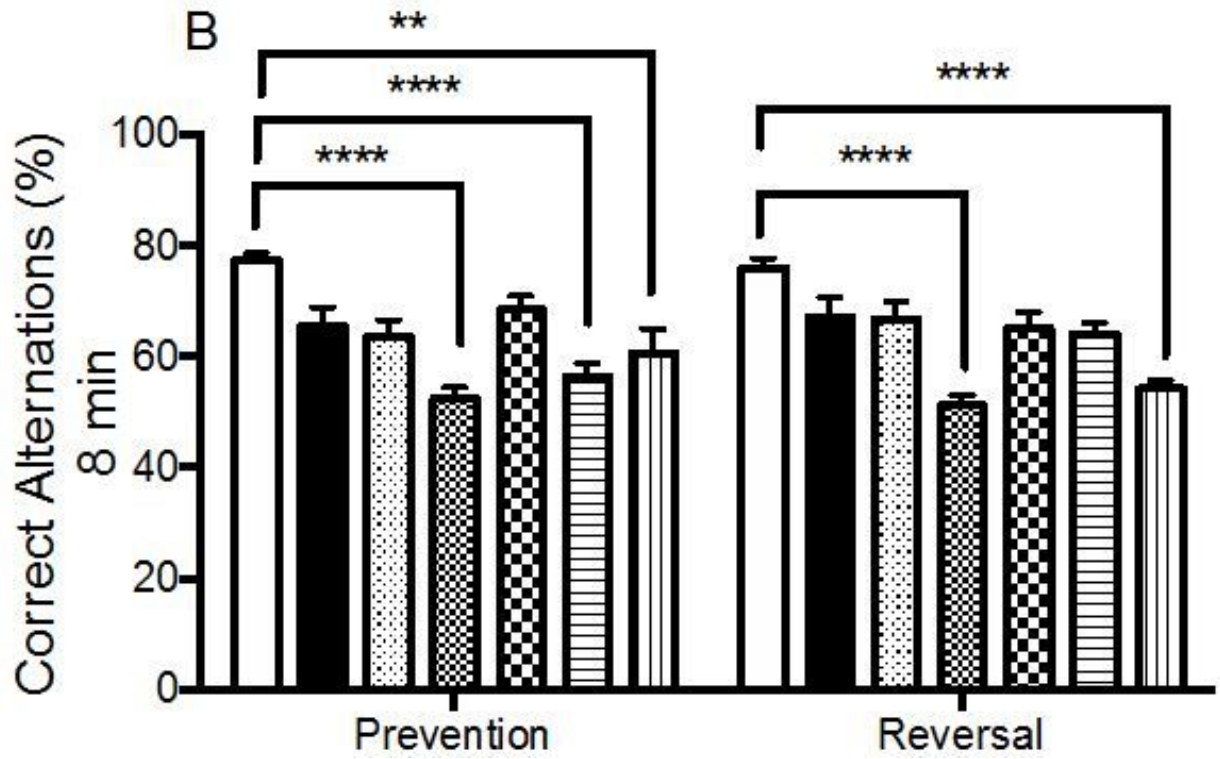

$\square$ Saline

EOAZ100

EOAZ200

$\$$ KET + Saline

W KET + EOAZ100

E KET + EOAZ200

IIII KET + OLZ

\section{Figure 3}

Effect of EOAZ on KET-induced social interaction and working memory deficits. Mice were treated with the essential oil from Alpinia zerumbet (EOAZ 50, 100 and $200 \mathrm{mg} / \mathrm{kg}$, p.o.) or $2 \mathrm{mg} / \mathrm{kg}$ olanzapine in the prevention and reversal protocols of KET- schizophrenia model and evaluated for social preference \% (A) 
and correct alternates \% in Y-maze test (B). Bars represent mean \pm SEM ( $n=8$ animals/group). ${ }^{*} P<0.05$, ${ }^{\star *} P<0.01,{ }^{* \star *} P<0.001,{ }^{* \star \star *} P<0.0001$ according to two-way ANOVA followed by Turkey's post-hoc test. Abbreviations: EOAZ: essential oil of Alpinia zerumbet; KET: ketamine; OLZ: olanzapine.

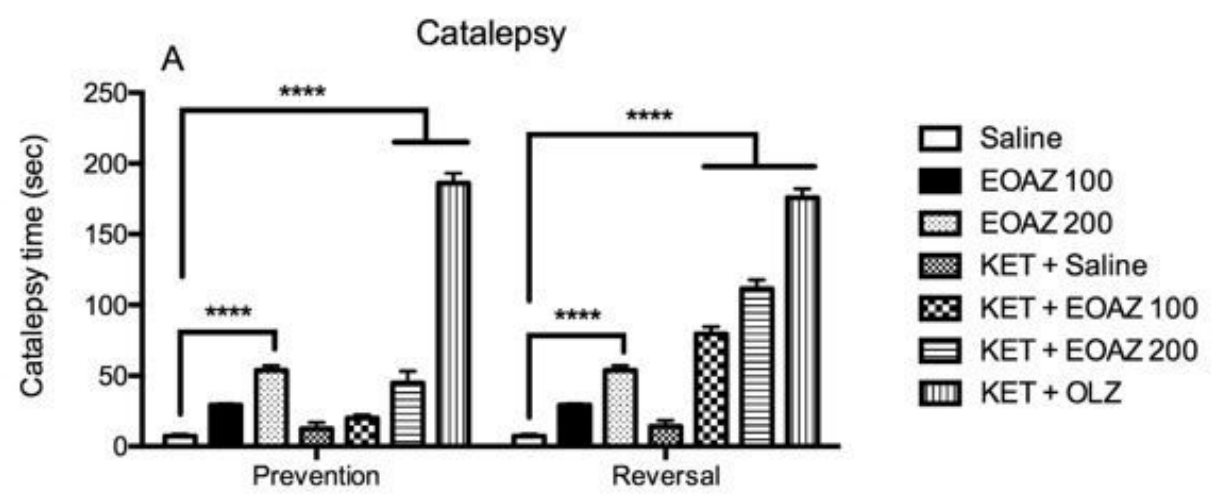

Weight Alterations - Prevention
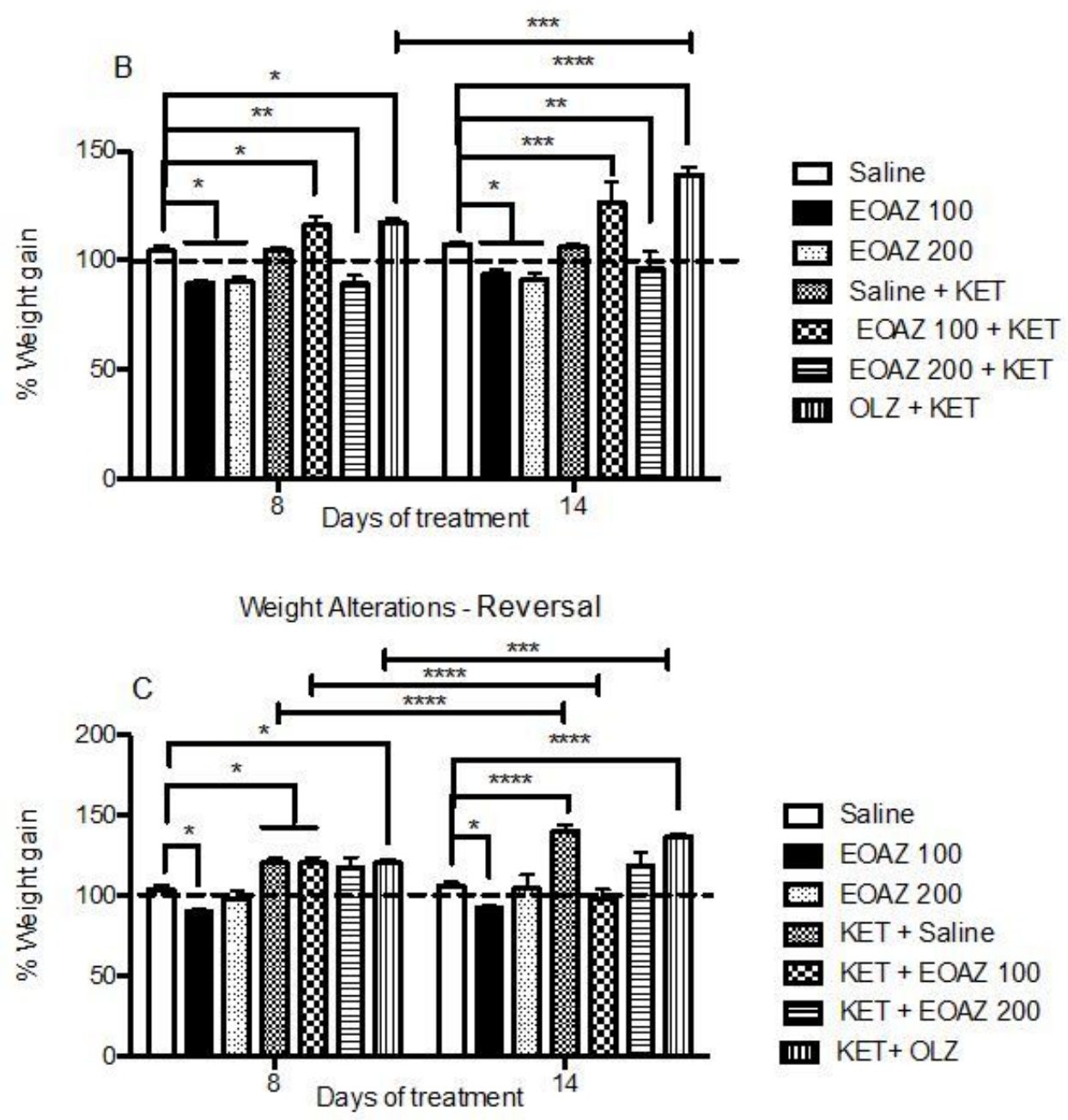

Figure 4

Evaluation of cataleptic effect and weight changes associated with EOAZ and OLZ in the KET schizophrenia model. Mice were treated with the essential oil from Alpinia zerumbet (EOAZ 50, 100 and 
$200 \mathrm{mg} / \mathrm{kg}$, p.o.) or $2 \mathrm{mg} / \mathrm{kg}$ olanzapine in the prevention and reversal protocols of KET-schizophrenia model and evaluated for catalepsy time(s) (A) and \% weight gain (B). Bars represent mean \pm SEM ( $n=8$ animals/group). ${ }^{\star} P<0.05,{ }^{*} P<0.01,{ }^{*} * \mathrm{P}<0.001,{ }^{*} * \star \mathrm{P}<0.0001$ according to two-way ANOVA followed by Turkey's post-hoc test. Abbreviations: EOAZ: essential oil of Alpinia zerumbet; KET: ketamine; OLZ: olanzapine.
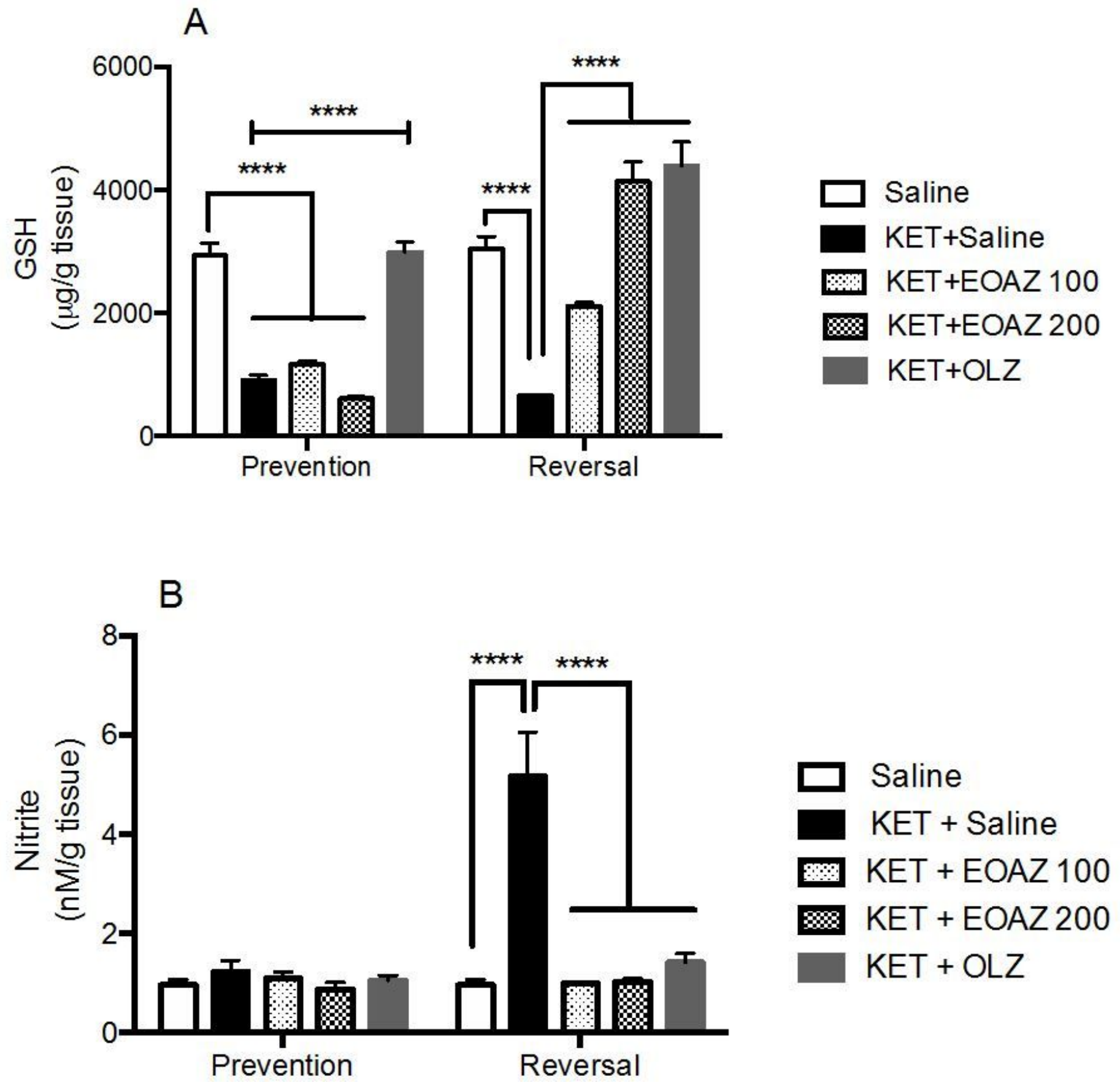

Figure 5

Effect of EOAZ and OLZ on KET-induced oxidative stress in mice hippocampus. Mice were treated with the essential oil from Alpinia zerumbet (EOAZ 50, 100, and $200 \mathrm{mg} / \mathrm{kg}$, p.o.) or $2 \mathrm{mg} / \mathrm{kg}$ olanzapine in the 
prevention and reversal protocols of KET-schizophrenia model. The hippocampus was dissected, and reduced GSH (A) and nitrite levels (B) were measured. Bars represent mean \pm SEM ( $n=8$ animals/group). ${ }^{*} P<0.05,{ }^{* *} P<0.01,{ }^{* \star *} P<0.001,{ }^{* \star * * P} P 0.0001$ according to two-way ANOVA followed by Turkey's posthoc test. Abbreviations: EOAZ: essential oil of Alpinia zerumbet; KET: ketamine; OLZ: olanzapine; GSH: glutathione.
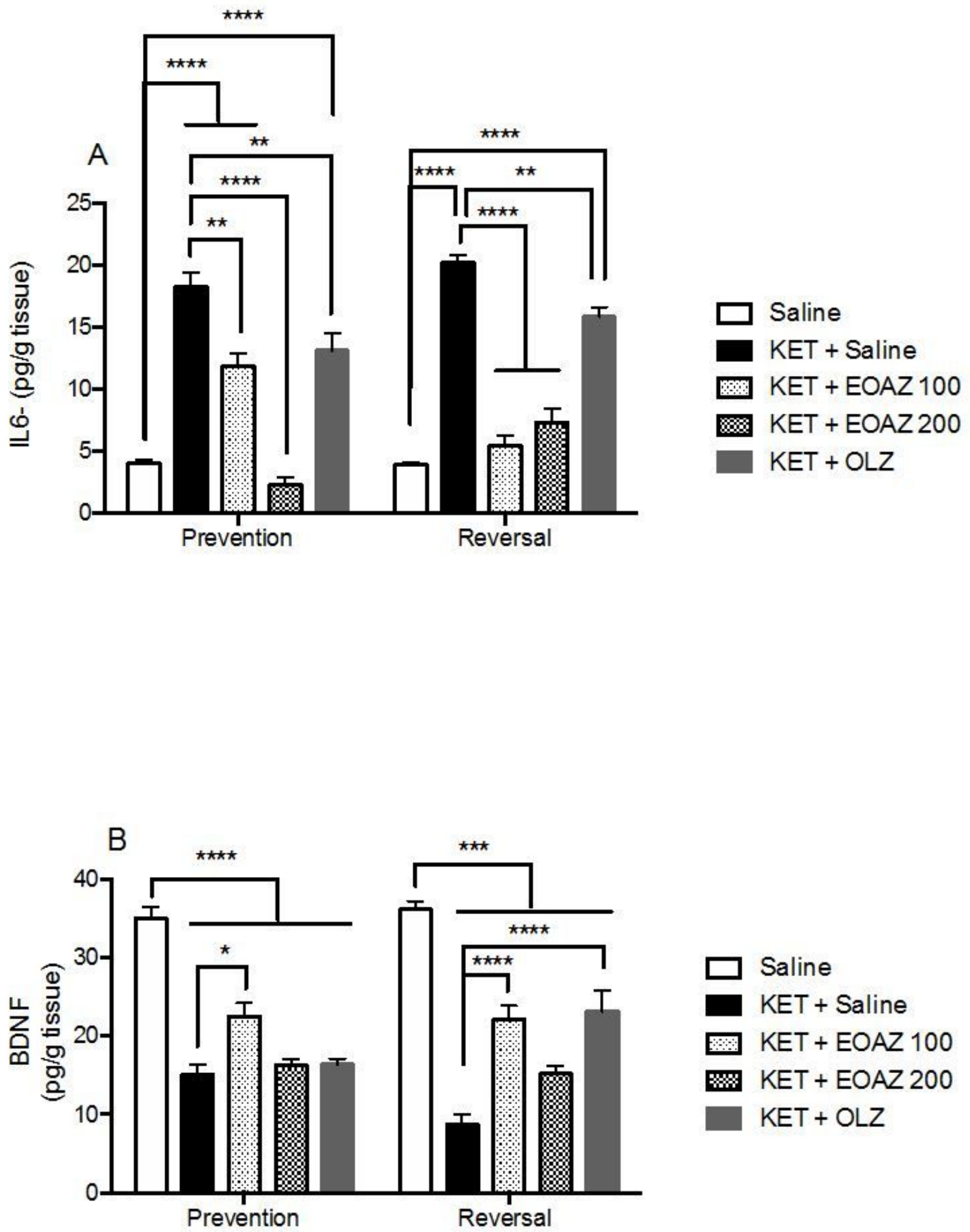

$\square$ Saline

KET + Saline

KET + EOAZ 100

KET + EOAZ 200

$\mathrm{KET}+\mathrm{OLZ}$

Figure 6 
Effect of EOAZ and OLZ on KET-induced IL- 6 and BDNF changes in mice hippocampus. Mice were treated with the essential oil from Alpinia zerumbet (EOAZ 50, 100, and $200 \mathrm{mg} / \mathrm{kg}$, p.o.) or $2 \mathrm{mg} / \mathrm{kg}$ olanzapine in the prevention and reversal protocols of KET-schizophrenia model. The hippocampus was dissected, and IL-6 ( $\mathrm{pg} / \mathrm{g}$ tissue) (A) and BDNF (pg/g tissue) (B) were measured. Bars represent mean \pm SEM ( $\mathrm{n}=8$

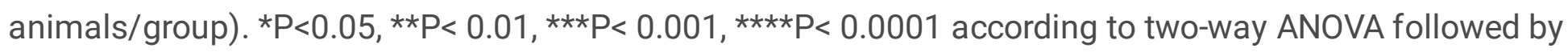
Turkey's post-hoc test. Abbreviations: EOAZ: essential oil of Alpinia zerumbet; KET: ketamine; OLZ: olanzapine; IL: interleukin; BDNF: brain-derived neurotrophic factor. 